\title{
Calcium Channel Currents in Isolated Guinea-pig Ventricular Cells Superfused with Ca-free EGTA Solution
}

\author{
Yutaka Iмото, Tsuguhisa Ehara, and Masayosi Goто* \\ Department of Physiology, Faculty of Medicine, \\ Kyushu University, Fukuoka, 812 Japan
}

\begin{abstract}
Changes in membrane currents seen in Ca-free, EGTA (1 mM)containing Tyrode solution (EGTA Tyrode), were studied in isolated guinea-pig ventricular cells, under the voltage clamp performed with a "G $\Omega$ seal" patch electrode. Application of the EGTA Tyrode (calculated $[\mathrm{Ca}]_{0}=1.3 \times 10^{-8} \mathrm{M}$ ) first eliminated the usual calcium current, but induced an extra inward current within $2 \mathrm{~min}$. The reversal potential of this current, as judged by the direction of the current change, was about $+25 \mathrm{mV}$ (without correction of a liquid junction potential of $-12 \mathrm{mV}$ ), but above this voltage a decaying outward current was observed. The decay of these inward and outward currents during depolarization was slow, but a large, nearly time-independent component was evident. These currents, regardless of their polarity and time course, were reduced by application of verapamil $\left(10^{-5} \mathrm{M}\right)$ and $\mathrm{Mg}(5 \mathrm{~mm})$, and were inactivated by pre-depolarizations. In Na-free EGTA Tyrode, the inward current disappeared but the outward current persisted at high voltages. These results suggest that in ventricular cells, reduction of external $\mathrm{Ca}$ concentrations to a nanomolar range induces a $\mathrm{Ca}$ channel current composed of an inward current carried by $\mathrm{Na}$, and an outward current, presumably carried by $\mathrm{K}$ ions. Because of the persistence of the apparently non-inactivating $\mathrm{Ca}$ channel current, the net membrane current evoked at voltages around $0 \mathrm{mV}$ remained close to zero, or even inward, after the decay of the time-dependent component, which was completed within a few hundreds ms. This characteristic $I-V$ relation was considered to be linked to the development of the long-lasting action potentials, with a plateau maintained at around $0 \mathrm{mV}$, in EGTA Tyrode.
\end{abstract}

Key words: ventricular cell, Ca-depletion, EGTA, Ca channel current, monovalent cation.

$\mathrm{Ca}$ ions play an important role in excitable membranes, and the electro-

Received for publication June 15, 1985

* Present address: School of Food and Nutrition, Nakamura Gakuen College, Fukuoka, 814 Japan 
physiological effects of varying the external $\mathrm{Ca}$ concentration have been extensively studied in various tissues. In cardiac muscle, lowering $[\mathrm{Ca}]_{0}$ generally prolongs the duration of the action potential. Extreme reduction of $[\mathrm{Ca}]_{0}$, with chelating agents such as EGTA, sometimes evokes prolonged action potentials of several seconds' duration (HofFMAN and SuckLING, 1956; Goto and ABE, 1964; RougIER et al., 1969; MiLler and MörChEN, 1978). The mechanism of this phenomenon is not fully understood. RougIer et al. (1969) and GARNIER et al. (1969) attributed the prolongation to development of the $\mathrm{Na}$ current, which involves slow inactivation kinetics, while MILLER and MörCHEN (1978) directed attention to Cadependent changes in $\mathrm{K}$ conductance. In studies done without chelating agents, URATA and GoTO (1982) suggested that the prolongation is mainly due to a suppression of the delayed rectifier and background $\mathrm{K}$ conductance. In addition, the prolonged action potentials produced by Ca-depleted fluid usually had a plateau with a low voltage level, which remains to be explained.

The aforementioned studies using chelating agents clearly indicated that $\mathrm{Ca}$ concentrations of even less than micromolar range exerted a profound effect on the cardiac membrane. Therefore, the rate and degree of diffusion of Ca-depleted fluid within the tissue may be a serious factor in interpreting the results of Ca-removal experiments (TRITTHART et al., 1973). In the present study, we reinvestigated the effects of Ca-removal, with or without chelating agents, on cardiac membranes, using isolated single myocytes. It is assumed that these preparations are almost free of the morphological factors related to incomplete diffusion. We attempted to elucidate changes in the membrane currents produced by $\mathrm{Ca}$-depletion in these cells.

\section{METHODS}

Cell preparation. We isolated single ventricular cells from the hearts of adult guinea-pigs ( $400-500 \mathrm{~g}$ ) by the procedure similar to that described by IRISAWA and KoKubun (1983). After intraperitoneal injection of pentobarbital $(60 \mathrm{mg} / \mathrm{kg})$, the animal was artificially ventilated and the thorax was opened. Heparin (300 unit $/ \mathrm{kg}$ ) was injected into superior vena cava and the aorta was cannulated in situ. The heart was then excised and perfused with $50 \mathrm{ml}$ normal Tyrode and $50 \mathrm{ml}$ nominally Ca-free Tyrode, succesively. Then "digestive solution" (see below) was perfused for $40 \mathrm{~min}$ at $37^{\circ} \mathrm{C}$. After this period, the heart was perfused with $100 \mathrm{ml}$ of KB medium (ISENBERG and KLÖCKNER, 1982a), and was placed in a dissecting dish filled with $\mathrm{KB}$ medium. The dispersed ventricular cells were obtained by gentle tearing of the tissue, and were kept in KB medium at room temperature. The digestive solution was made by adding $20 \mathrm{mg}$ collagenase (Sigma, Type I) and $50 \mathrm{mg}$ bovine serum albumin (Sigma, essentially fatty acid free) to $50 \mathrm{ml}$ of nominally Ca-free Tyrode.

Solutions. The compositions of the main external and internal (pipette) 
Table 1. Composition of solutions.

A. External solutions

\begin{tabular}{|c|c|c|c|c|c|c|c|c|}
\hline & \multicolumn{6}{|c|}{ Added (mM) } & \multicolumn{2}{|c|}{ Calculated (M) } \\
\hline & $\mathrm{NaCl}$ & Tris-Cl & $\mathrm{KCl}$ & $\mathrm{MgCl}_{2}$ & $\mathrm{CaCl}_{2}$ & EGTA & {$[\mathrm{Ca}]_{0}$} & {$[\mathrm{Mg}]_{0}$} \\
\hline $\begin{array}{l}\text { Normal Tyrode } \\
\text { Nominally }\end{array}$ & 150 & - & 5.4 & 0.5 & 1.8 & - & - & - \\
\hline Ca-free Tyrode & 150 & - & 5.4 & 0.5 & - & 1.0 & $2 \times 10^{-5 *}$ & - \\
\hline EGTA Tyrode & 150 & - & 5.4 & $\begin{array}{r}0.5 \\
(5.0)\end{array}$ & - & 1.0 & $\begin{array}{r}1.3 \times 10^{-8} \\
\left(1.4 \times 10^{-9}\right.\end{array}$ & $\begin{array}{l}4.8 \times 10^{-4} \\
4.9 \times 10^{-3}\end{array}$ \\
\hline $\begin{array}{l}\text { Na-free, } \\
\text { EGTA Tyrode }\end{array}$ & - & 150 & 5.4 & 0.5 & - & 1.0 & $1.3 \times 10^{-8}$ & $4.8 \times 10^{-4}$ \\
\hline B. Pipette s & ation $(\mathrm{n}$ & & & & & & & \\
\hline $\mathrm{K}$-aspartate & $\mathrm{KCl}$ & EG & & ATP & Glucos & & EPES & [Ca] \\
\hline 110 & 20 & 1. & & 5.0 & 10 & & 3.2 & $.2 \times 10^{-8}(\mathrm{M})$ \\
\hline
\end{tabular}

All the external solutions contained $5.5 \mathrm{~mm}$ glucose and $10 \mathrm{~mm}$ HEPES. The pH were adjusted to 7.4 in external solutions, and to 7.2 in pipette solutions. The free calcium and magnesium concentrations were calculated, using the binding constants for these cations to EGTA (Miller and Moisescu, 1976; Harafuji and Ogawa, 1980).

* The contaminated calcium ion concentration in nominally Ca-free Tyrode was measured, using a Ca-sensitive electrode (Orion Research, 701A).

solutions used are litsed in Table 1. The Ca concentration contaminated in our nominally Ca-free Tyrode solution was around $2 \times 10^{-5} \mathrm{M}$, as measured with an ion analyser with a Ca-sensitive electrode (Orion Research, 701A). To reduce free $\mathrm{Ca}, 1 \mathrm{~mm}$ EGTA was added to the nominally Ca-free solutions. The calculated levels of $\mathrm{Ca}$ and $\mathrm{Mg}$ concentration in these solutions are also shown in Table 1. In some experiments, verapamil (Eisai) and 4-aminopyridine (Tokyo Kasei) were used.

Patch electrode. Patch electrodes were fabricated from glass capillaries (outer diameter $1.5 \mathrm{~mm}$, inner diameter $1 \mathrm{~mm}$ ) by two-stage pulling, and the tip was polished with heat (HAmiLl et al., 1981). The electrodes had the resistance of 2-4 M $\Omega$, when filled with an internal solution.

Recording technique. The isolated cells were dispersed in a recording chamber $(0.2 \mathrm{ml}$ in volume), which was placed on the stage of an inverted microscope. The chamber was continuously perfused with Tyrode solution with a temperature of $34-36^{\circ} \mathrm{C}$, at the rate of $1 \mathrm{ml} / \mathrm{min}$. The procedure to establish the configuration of whole-cell recording was much the same as described by HAMILL et al. (1981), except that the patch electrode was connected to a single microelectrode voltage clamp system with a sample and hold operation (Dagan, 8100). Stimulation, voltage clamp, and current clamp were performed as described elsewhere (YATANI et al., 1984; JoSEPHSON et al., 1984).

The liquid junction potential developing at the tip of the electrode filled with pipette solution was $11.5 \pm 0.4 \mathrm{mV}(n=5)$, as was determined by following the

Vol. 35, No. 6, 1985 
procedure of MATSUDA and NomA (1984). With this approach, the measurement of membrane potential is about $12 \mathrm{mV}$ too positive, as correction for voltage was not made in this study.

Membrane potentials and membrane currents were displayed on an oscilloscope (Nihon Kohden, VC10), and photographed or stored on magnetic tape (TEAC, R211).

\section{RESULTS}

When the guinea-pig ventricular cells were exposed to EGTA Tyrode (calculated $[\mathrm{Ca}]_{0}=1.3 \times 10^{-9} \mathrm{M}$ ), the action potential was at first abortive, but within $2 \mathrm{~min}$ there was a marked lengthening of the action potential duration (Fig. 1A). The duration sometimes lasted over $10 \mathrm{~s}$. A characteristic feature of the prolonged action potential was that its plateau level was maintained at a low voltage $(-10$ to

A

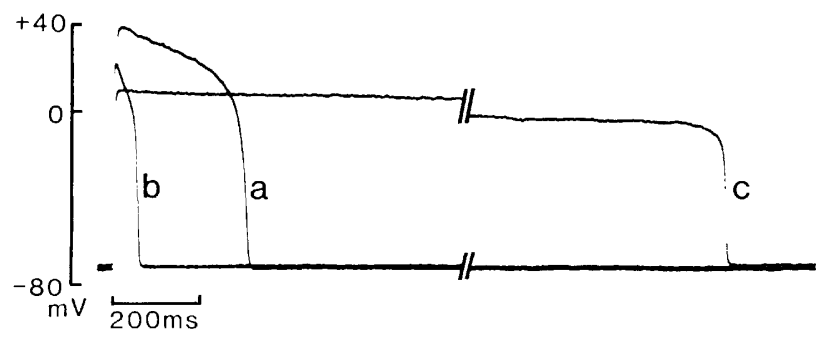

C

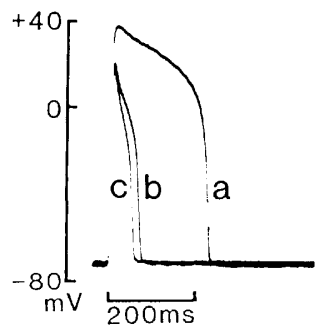

B

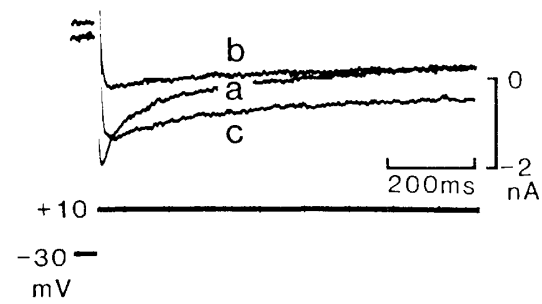

D

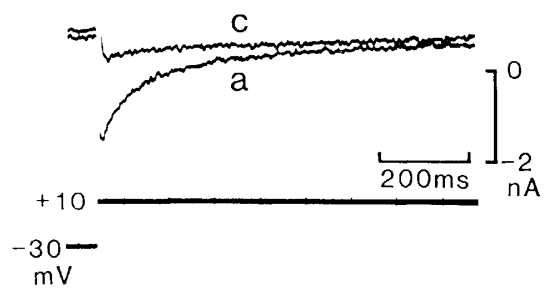

Fig. 1. Effects of Ca-free Tyrode solution, containing a $1 \mathrm{~mm}$ EGTA (EGTA Tyrode) and nominally Ca-free Tyrode solution, on action potential and membrane current. A: action potential in normal Tyrode (a), $90 \mathrm{~s}$ (b), and $100 \mathrm{~s}$ (c) after exposure to EGTA Tyrode. The break in trace $\mathrm{c}$ is a $10 \mathrm{~s}$ gap. B: superimposed record of membrane currents, (upper trace) observed during the experiment shown in A. Clamp steps to $+10 \mathrm{mV}$ (lower trace) were applied from a holding potential of $-30 \mathrm{mV}$. Each current trace $(a, b$, and $c)$ was obtained a few $s$ after the time at which each action potential in A ( $a, b$, and $c$ ) was observed. C: action potential in normal Tyrode (a), 3 min (b), and 5 min (c) after exposure to nominally Ca-free Tyrode. D: membrane currents observed during the experiment shown in C. Conditions, similar to B. 
$+10 \mathrm{mV})$. The resting potential decreased in EGTA Tyrode by a few $\mathrm{mV}$, in most cases.

To clarify the changes in membrane currents responsible for the above changes in the action potential, a voltage clamp was utilized. We generally held the membrane potential at $-30 \mathrm{mV}$, in order to inactivate the fast $\mathrm{Na}$ system, and then imposed the clamp step to various voltages. Figure 1B shows the membrane currents in response to the clamp step at $+10 \mathrm{mV}$, observed during the course of the experiment shown in Fig. 1A. On exposure of the cell to EGTA Tyrode, the $\mathrm{Ca}$ current $\left(I_{\mathrm{Ca}}\right)$ first markedly decreased (Fig. 1B, trace b). However, at the time when the action potential was prolonged, the current during the depolarizing step showed a large inward shift (trace c). In contrast, nominally Ca-free Tyrode (contaminated $\left.[\mathrm{Ca}]_{0}=2 \times 10^{-5} \mathrm{M}\right)$ produced only a depression of the action potential (Fig. 1C), with a decrease in $I_{\mathrm{Ca}}$ (Fig. 1D).

Thus, a decrease in $[\mathrm{Ca}]_{0}$ to contaminated levels greatly reduced $I_{\mathrm{Ca}}$, as expected, but a more complete elimination of $\mathrm{Ca}$ induced the change in the membrane current shown in Fig. $1 \mathrm{Bc}$. It is unlikely that EGTA itself affected the membrane's electrical property, since the Tyrode solution containing $1.8 \mathrm{~mm} \mathrm{Ca}$ and $1 \mathrm{~mm}$ EGTA exerted effects similar to those of low-Ca Tyrode without EGTA (not shown).

Figure 2 shows the result of a more detailed voltage clamp study. In a normal Tyrode, depolarizing clamp steps up to $+40 \mathrm{mV}$ always produced a decaying inward current $\left(I_{\mathrm{Ca}}\right)$. In contrast, in EGTA Tyrode, there apparently was a reversal of the currents elicited, the reversal potential being $+25.5 \pm 3.1 \mathrm{mV}$ (mean \pm S.D., $n=6$ ). Below this voltage, the current was an inward one, decaying slowly, as noted before, and above it, a decaying outward current was observed (Fig. 2A). The threshold voltage for the inward current was about $-30 \mathrm{mV}$. The voltage for the maximum peak inward current in EGTA Tyrode was about $10 \mathrm{mV}$ more negative than that in a normal Tyrode (Fig. 2B).

Since the currents induced in an EGTA Tyrode showed little or no time-dependence during the later phase of $800 \mathrm{~ms}$ pulses at all voltages (Fig. 2A), this solution appeared to induce not only a clearly decaying current but also an almost time-independent current. The late current levels at the end of $800 \mathrm{~ms}$ pulse were less outward in an EGTA Tyrode than in normal in the voltage range between -30 and $+30 \mathrm{mV}$, and were net inward at voltages around $0 \mathrm{mV}$, in an EGTA Tyrode (Fig. 2B). It is very likely that this characteristic $I-V$ relation is related to the prolongation of the action potential in this solution (Fig. 1A). The curves of late current levels in normal and EGTA Tyrodes crossed at $30 \mathrm{mV}$, as if the change in the late current also had a reversal potential (Fig. 2B).

If the currents induced by EGTA Tyrode represent or include those flowing through the Ca channel (RougIER et al., 1969), they should be sensitive to blockers of these channels. In the experiment shown in Fig. 3, we examined the effect of verapamil. Verapamil strongly suppressed the inward current during moderate 

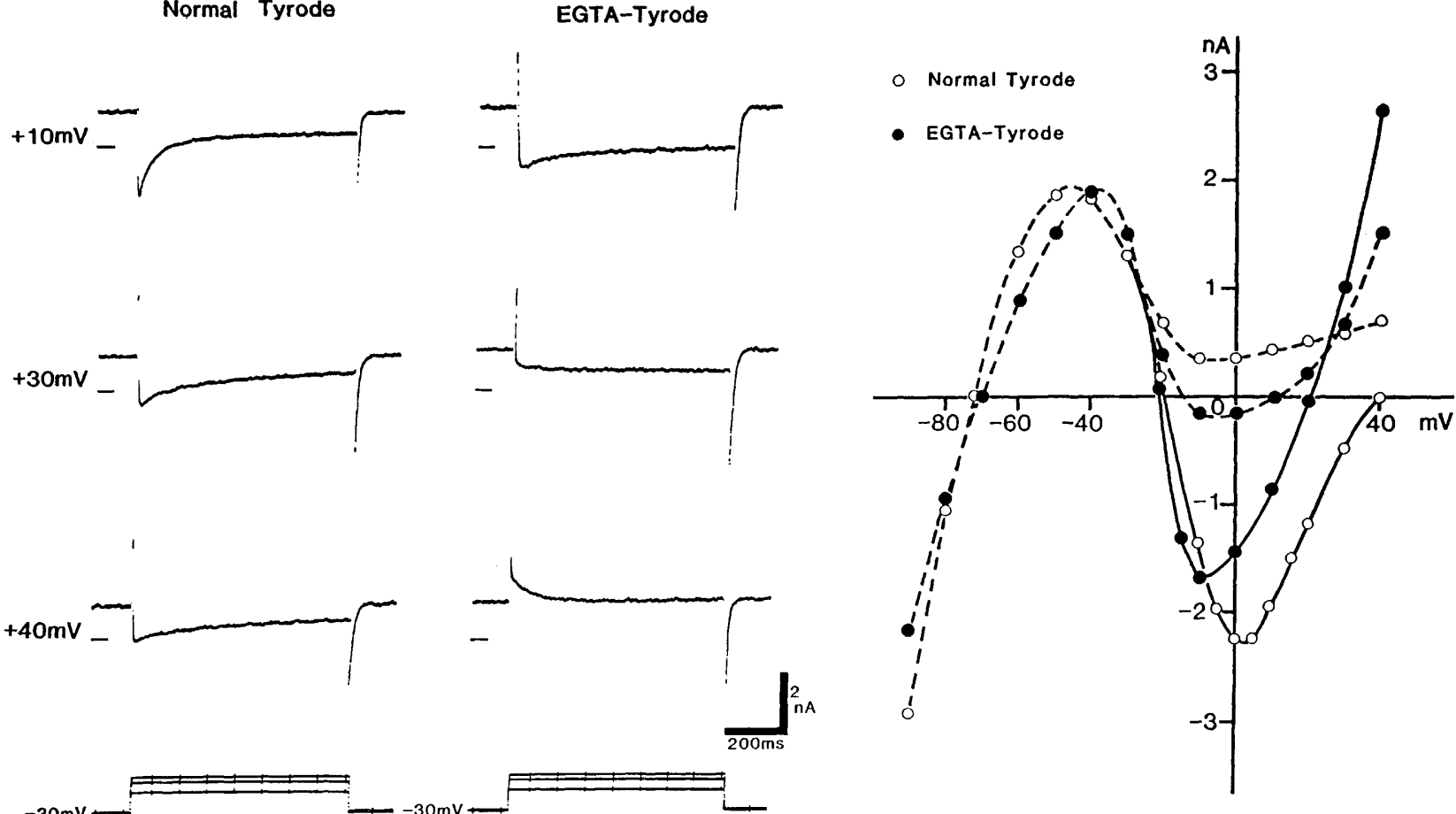

Fig. 2. Effects of EGTA Tyrode on membrane currents. A: original records of membrane currents in normal Tyrode (left row), and in EGTA Tyrode (right row). Voltage steps are shown at the bottom of each row. Test potentials are indicated at the left. Holding potential, $-30 \mathrm{mV}$. Short horizontal bar at left of each current trace shows zero current level. B: $I-V$ relationship in normal Tyrode (open circles) and EGTA Tyrode (filled circles). Continuous lines indicate peak inward or outward current at the beginning of pulses, and broken lines indicate late current levels at $800 \mathrm{~ms}$. Current was calculated as the difference from zero current level. 
A

$-10 \mathrm{mV}$

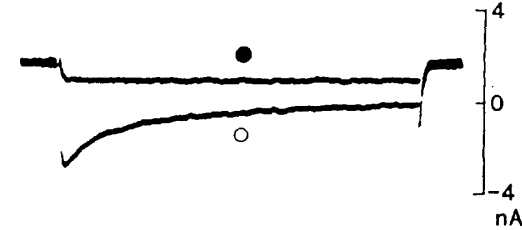

$+20 \mathrm{mV}$

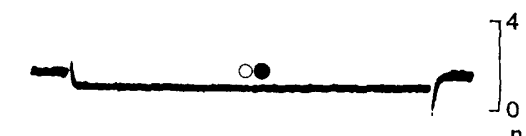

$+40 \mathrm{mV}$

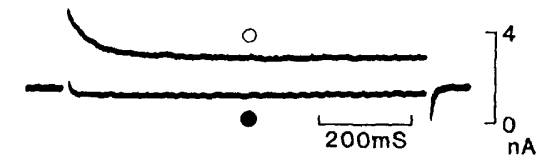

B

- EGTA-Tyrode

- + Verapamil

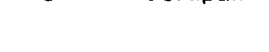

Fig. 3. Effects of verapamil on membrane currents in EGTA Tyrode. A: original records of membrane currents, before (open circles) and $5 \mathrm{~min}$ after (filled circles) exposure to verapamil $\left(10^{-5} \mathrm{M}\right)$. Holding potential, $-30 \mathrm{mV}$. Test potential is indicated at the left of each trace. B: I-V relationship before (open circles) and after (filled circles) exposure to verapamil. Continuous line indicates peak inward or outward current, and broken lines indicate late current levels at $800 \mathrm{~ms}$. For verapamil, only the late current is plotted, because the current showed little or no time-dependence at all voltages, after application of verapamil. Note that verapamil had no effect on the currents at $+20 \mathrm{mV}$, this being where the current was reversed before the use of verapamil. Clamp pulse interval, $8 \mathrm{~s}$. 


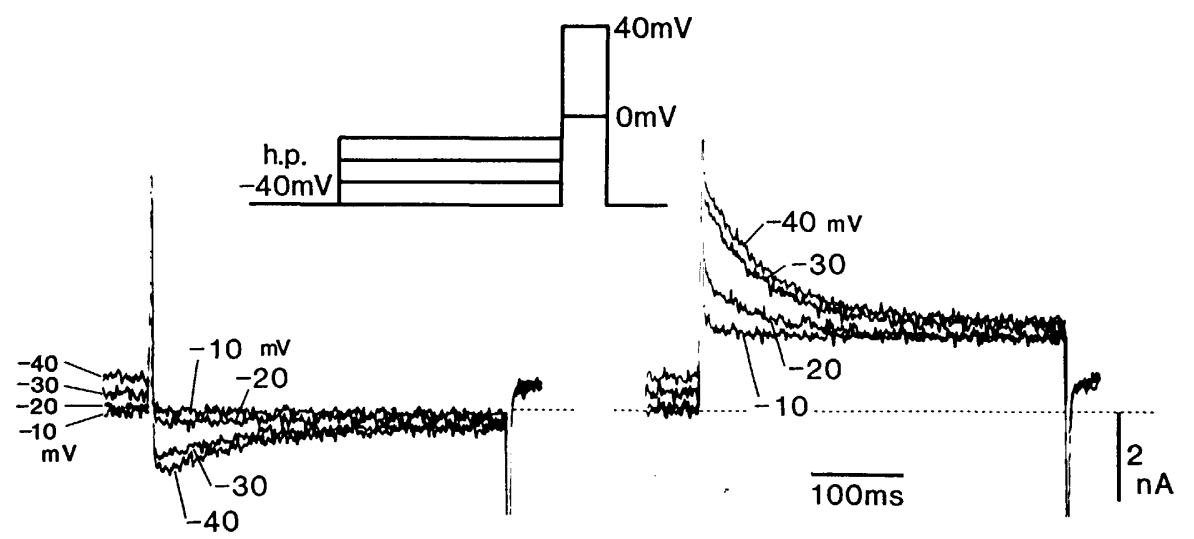

Fig. 4. Effect of pre-depolarization on inward and outward currents induced by EGTA Tyrode. Four hundred $\mathrm{ms}$ test pulses to 0 (left) and $+40 \mathrm{mV}$ (right) were applied, with or without pre-depolarizations. Only the currents elicited by test pulses are shown. The figures attached to each trace indicate prestep potential. Inset shows the voltage protocol. Holding potential, $-40 \mathrm{mV}$. Duration of prestep, $2 \mathrm{~s}$.

depolarizations as well as the decaying outward current at high voltages. At $+20 \mathrm{mV}$, where the current was almost flat (reversal) before the use of verapamil, the drug had little effect. It is important that not only the clearly time-dependent component but also the time-independent or very slow component was reduced by verapamil, so that in Fig. 3B, all three $I-V$ relation curves crossed at almost the same point (at $20 \mathrm{mV}$ in this case). These results may rule out the possibility that the changes in the late current level produced by the EGTA Tyrode (Fig. 2B) reflected only a change in the background conductance.

Inorganic $\mathrm{Ca}$ channel blockers, such as $\mathrm{Co}, \mathrm{Cd}$, or $\mathrm{Mn}$, were not tested, because they strongly bind with EGTA. Mg ions bind with EGTA only weakly, and they are thought to suppress the $\mathrm{Ca}$ channel current, particularly in the absence of Ca (GARNIER et al., 1969). We observed that increasing $[\mathrm{Mg}]_{0}$ in EGTA Tyrode to $5 \mathrm{~mm}$ exerted effects similar to those of verapamil on the membrane currents (not shown). Like verapamil, $\mathrm{Mg}$ had little effect on the current at the reversal potential. Thus, the currents induced by EGTA Tyrode were sensitive to $\mathrm{Ca}$ channel blockers. It is noteworthy that the late current levels at voltages around $0 \mathrm{mV}$ became clearly outward, after these blockers (Fig. 3B).

The steady state inactivation of the Ca channel currents depends on the membrane potential. Figure 4 shows the result of the experiments in which we examined whether the currents induced by EGTA Tyrode were inactivated by preceding depolarizing steps. The figure shows that the magnitude of the inward current at $0 \mathrm{mV}$, as well as the outward current at $+40 \mathrm{mV}$, decreased with the strengthening of the predepolarizations, as expected, for the Ca channel current. In addition, these currents were not influenced by $2 \mathrm{~mm} 4$-aminopyridine, a compound con- 
A

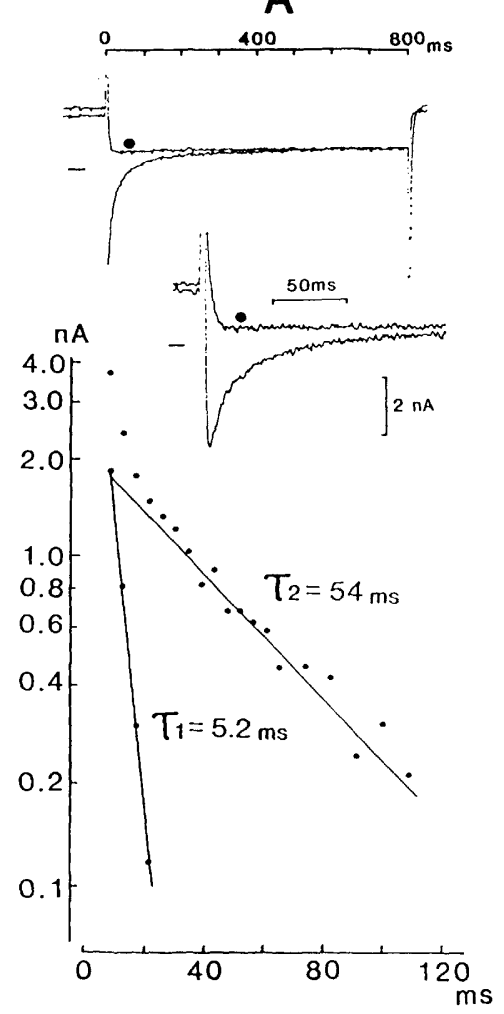

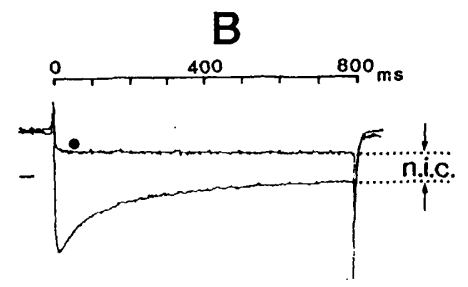

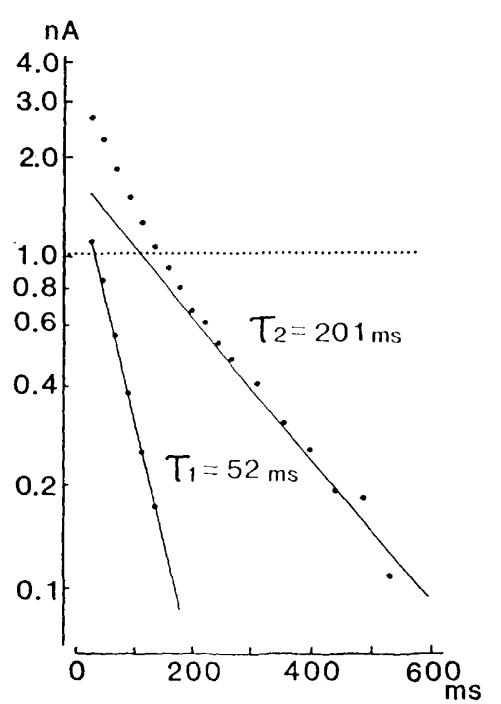

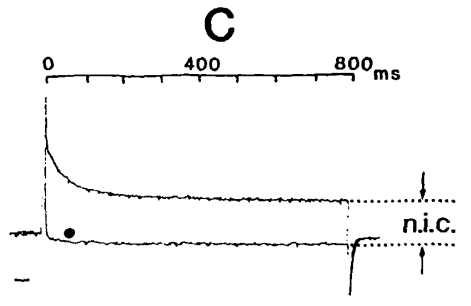

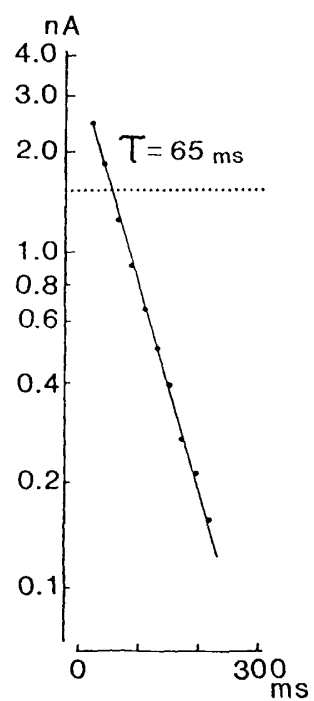

Fig. 5. Time course of verapamil-sensitive current in normal and EGTA Tyrode. Currents were recorded before and after verapamil, and magnitude of difference current was plotted against time on a logarithmic scale. Holding potential, $-30 \mathrm{mV}$. A: current at test voltage of $0 \mathrm{mV}$ in normal Tyrode. B: similar to A, but in EGTA Tyrode. C: current at $+40 \mathrm{mV}$ in EGTA Tyrode. Upper panels show superimposed, original records of currents, obtained before and after (dot) verapamil. In A, the record with a faster time scale is also shown. In B and C, time-dependent components were obtained by regarding the current level at 800 ms (non-inactivating component; n.i.c.) as their asymptote. Dotted lines in the graph show the magnitude of n.i.c. Values 
A
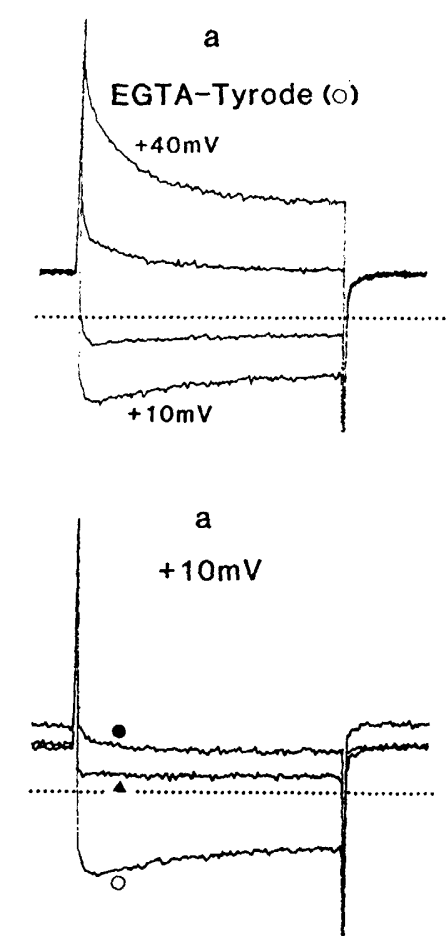
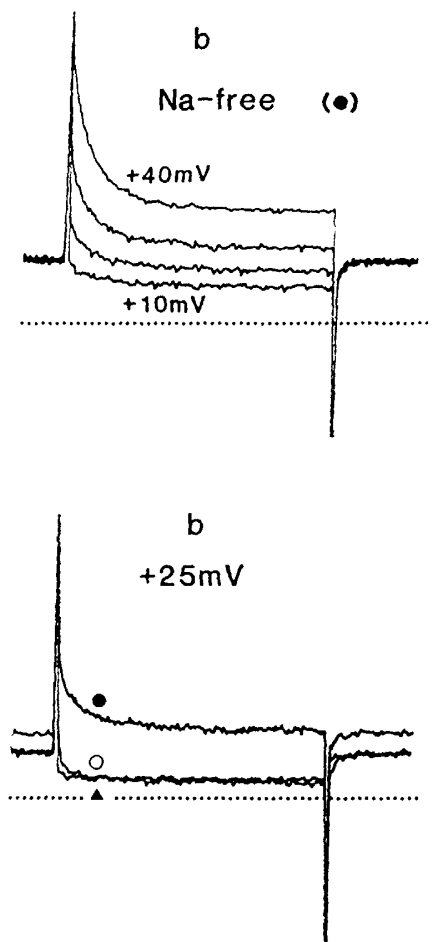

$c$
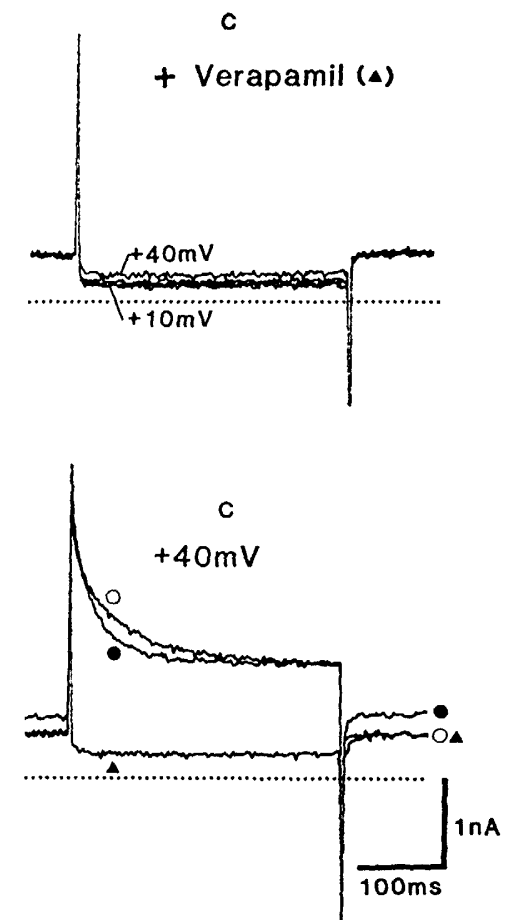

Fig. 6. Elimination of inward current by Na-removal, and of remaining outward current by verapamil in EGTA Tyrode. A: membrane currents in EGTA Tyrode (a), Na-free EGTA Tyrode (b), and Na-free EGTA Tyrode containing $10^{-5} \mathrm{M}$ verapamil (c). Currents recorded during $300 \mathrm{~ms}$ depolarizing steps to $+10,+20,+30$, and $+40 \mathrm{mV}$ are shown. Holding potential, $-40 \mathrm{mV}$. B: comparison of currents in EGTA Tyrode (open circles), Na-free EGTA Tyrode (filled circles), and Na-free EGTA Tyrode containing verapamil (filled triangles), at three voltages $(+10,+25$, and $+40 \mathrm{mV})$. Dotted lines show zero current levels. 
sidered to block the transient outward current in cardiac muscles (KENYON and GiBBons, 1979). The results presented so far are consistent with the hypothesis that both the inward current during moderate depolarizations, and the outward current at high voltages observed in EGTA Tyrode, were the Ca channel current, even though their time course was different from that of the ordinary $I_{\mathrm{Ca}}$.

The action potential in EGTA Tyrode had a plateau maintained at around $0 \mathrm{mV}$ (Fig. 1A). Therefore, in Fig. 5A and B, we analyzed the time course of the verapamil-sensitive current at this voltage, in both a normal and an EGTA Tyrode solution. In the normal Tyrode, the current appeared to inactivate completely during depolarization (Fig. 5A). The decay of the current could be fitted with two exponentials, the corresponding time constant being 5.2 and $54 \mathrm{~ms}$, at $0 \mathrm{mV}$. These values are comparable to those for the $\mathrm{Ca}$ current reported by other investigators (ISENBERG and KLöCKNER, 1982b; IRISAWA and KoKUBUn, 1983).

In EGTA Tyrode, the current had a non-inactivating component. Therefore, we analyzed the time course, regarding the current level at the end of $800 \mathrm{~ms}$ pulse as an asymptote for the time-dependent component. The former was presumed to represent the amount of the non-inactivating component (n.i.c.). This analysis revealed two large time constants $(52 \mathrm{~ms}$ and $201 \mathrm{~ms})$, responsible for the decay of the inward current (Fig. 5B). Thus the inactivation of the $\mathrm{Ca}$ channel current in EGTA Tyrode is considerably slow, compared with that in the normal Tyrode. However, the decaying time constants are still too small to explain the action potential of several seconds' duration (Fig. 1A). Figure 5C shows an additional analysis of the decay of the outward current at large positive potentials. In this case, however, only one time constant was detected, but this point was not studied further.

Rougier et al. (1969) suggested that in the case of the frog atrium, the $\mathrm{Ca}$ channel current elicited in the absence of divalent cations is carried by $\mathrm{Na}$ ions. We attempted to determine the ion species responsible for the currents induced by EGTA Tyrode, under the present conditions. In the experiment shown in Fig. 6, we first omitted the external $\mathrm{Na}$ from EGTA Tyrode (Tris-Cl substitution), and then applied verapamil. When $\mathrm{Na}$ was removed, the decaying inward current observed at voltages up to $+20 \mathrm{mV}$ disappeared, with an outward shift of the late current levels at voltages up to $+30 \mathrm{mV}$ occurring. Also, a decaying outward current began to develop at +10 to $+20 \mathrm{mV}$ (Fig. $6 \mathrm{Ab}$ ). On the other hand, $\mathrm{Na}$ removal appeared to have little effect on the current at $+40 \mathrm{mV}$ (Fig. $6 \mathrm{Bc}$ ). This is important, because it indicates that the decaying outward current was carried mainly by ions other than Na. Further addition of verapamil greatly reduced the outward currents, and the currents after verapamil administration showed little time-dependence, at all voltages (Fig. $6 \mathrm{Ac}$ ), as noted before (Fig. 3). At $+25 \mathrm{mV}$, the current after the administration of verapamil was quite similar to the control current observed in EGTA Tyrode (Fig. $6 \mathrm{Bb}$ ). 

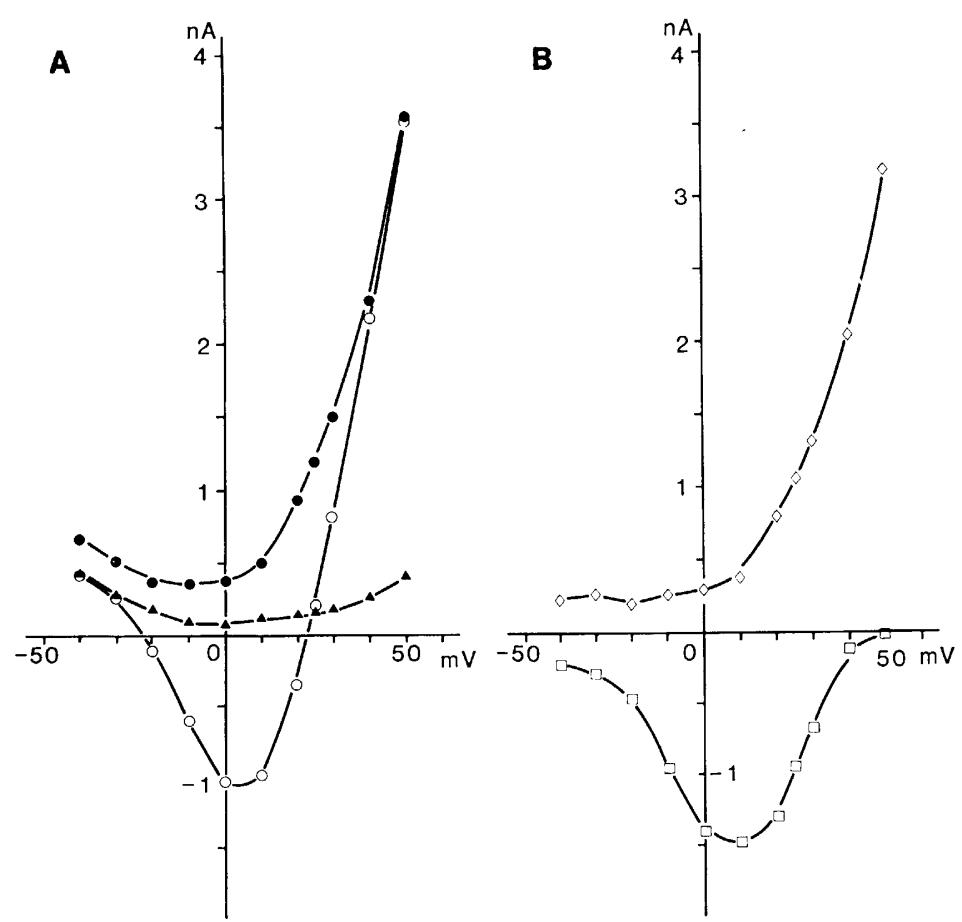

Fig. 7. Estimation of inward $\mathrm{Na}$ current and outward current through the $\mathrm{Ca}$ channel. A: $I-V$ relationships obtained from the experiment shown in Fig. 6. Peak inward or outward current in EGTA Tyrode (open circles), Na-free EGTA Tyrode (filled circles), and $\mathrm{Na}$-free EGTA Tyrode containing verapamil (filled triangles), are plotted against the test potential. Holding potential, $-40 \mathrm{mV}$. B: $I-V$ relationships of Na-sensitive current (squares) and verapamil-sensitive outward current (diamonds). Na-sensitive current was obtained as the difference between the currents, before and after $\mathrm{Na}$ removal (open circles minus filled circles in A). In the same manner, the verapamil-sensitive outward current was obtained, it being measured as the difference between the currents before and after the addition of verapamil (filled circles minus filled triangles in A).

The above results suggest that the current, in the presence of EGTA, is a Ca channel current, composed of an inward $\mathrm{Na}$ current and an outward current, carried mainly by other ions. The latter ions are very likely $\mathrm{K}$ ions, since they are the major intracellular cation species. Our interpretation of the results shown in Fig. 6 is as follows. Na removal eliminated the inward $\mathrm{Na}$ component, leaving the outward $\mathrm{K}$ component, which in turn led to a general increase in the outward currents (Fig. $6 \mathrm{Ab}$ ). The low Na-sensitivity of the current at $+40 \mathrm{mV}$ may be explained, if we accept the fact that this voltage was near the reversal potential for $\mathrm{Na}$ ions in EGTA Tyrode, and if the intracellular $\mathrm{Na}$ concentration decreased sufficiently during exposure to Na-free EGTA Tyrode. Verapamil further eliminated the remaining $\mathrm{K}$ component. If the reversal potential of the current in 
EGTA Tyrode, as determined by the direction of the current change, represents the potential at which the magnitudes of both the $\mathrm{Na}$ and $\mathrm{K}$ components are the same, verapamil should not affect the current at this voltage, in this solution (Fig. 3), but should alter the current at the same voltage after Na-removal, leaving a current similar to that in EGTA Tyrode (Fig. $6 \mathrm{Bb}$ ).

The Na-sensitive component was larger than the residual verapamil-sensitive component, at voltages around $0 \mathrm{mV}$ (Fig. $6 \mathrm{Ba}$ ). This may indicate that the $\mathrm{Na}$ component was the major determinant of the $I-V$ relation at these voltages.

Based on the above interpretations, we attempted to estimate the amounts of $\mathrm{Na}$ and $\mathrm{K}$ components, at various voltages. Figure 7B shows the $I-V$ relations of the Na-sensitive current and the verapamil-sensitive current, from a Na-free solution obtained in the experiment, shown in Fig. 6. The predicted $\mathrm{K}$ current showed an outward rectification at higher voltages. Such an outward rectification has also been noted for the $\mathrm{Ca}$ channel current carried by monovalent ions in ventricular cells (LeE and TSIEN, 1982, 1984), bovine chromaffin cells (FENWICK et al., 1982) and mouse B lymphocytes (Fukushima and Hagiwara, 1985). The predicted $\mathrm{Na}$ current had a voltage-dependency, similar to that usually seen for $I_{\mathrm{Ca}}$. However, Fig. 7A and B show that the presence of the outward current can make the voltage for the maximum of total inward current in EGTA Tyrode look apparently less positive than that of the Na current. This may partly explain the negative shift of the $I-V$ relation of the peak inward current produced by EGTA Tyrode (Fig. 2B), although the surface charge effect of the Ca-depleted fluid can also be a factor.

\section{DISCUSSION}

Mechanism of action potential prolongation. The present study suggested that, in guinea-pig ventricular cells, a Ca-free Tyrode solution, containing $1 \mathrm{~mm}$ EGTA (EGTA Tyrode), induced a Ca channel current, which was probably carried by $\mathrm{Na}$ and $\mathrm{K}$ ions. This current was composed of a clearly inactivating component, and a nearly time-independent component. Because of the persistence of the latter component, the net membrane current at voltages around $0 \mathrm{mV}$ continued to be inward, even after the inactivating component decayed. We suggest that this characteristic $I-V$ relation explains why the long-lasting action potential, with a depressed plateau, develops in EGTA Tyrode. The time course of the inactivating component was too fast to explain the prolongation of the action potential, although it was definitely slower than that of the normal $I_{\mathrm{Ca}}$ (Fig. 5). Since, in EGTA Tyrode, the inward current was greatly reduced by Na-removal at voltages up to $+10 \mathrm{mV}$ (Figs. 6 and 7), we consider that the non-inactivating $\mathrm{Na}$ current through the $\mathrm{Ca}$ channel, played a major role in producing that action potential.

ROUGIER et al. (1969) suggested that, in the case of frog atrium, slow Na current 
contributed to the prolongation of the action potential in a Ca-free, EDTA-containing solution. However, they stated that the current inactivated 2 to 3 times more slowly than the normal $I_{\mathrm{Ca}}$. They also directed no attention to changes in the late current levels during depolarizing steps. URATA and Goto (1982) and Goto et al. (1982), observed an inward shift of late current during depolarization in the frog atrium exposed to a Ca-free solution, and attributed it to the slow inactivation of $\mathrm{Na}$ current associated with a depression of the delayed rectifier and background $\mathrm{K}$ conductance. However, they neither measured the reversal potential of the slow current change nor examined the effects of $\mathrm{Ca}$ channel blockers on the late current. Therefore, in the frog atrium, the possibility of the persistence of non-inactivating $\mathrm{Na}$ current through the $\mathrm{Ca}$ channel cannot be ruled out.

In frog ventricular tissue, MILleR and MörCHEN (1978) attributed the prolongation of the action potential in EGTA solution to a decrease in $\mathrm{K}$ conductance. Their main argument was that the prolongation was not inhibited by $\mathrm{D} 600$, a $\mathrm{Ca}$ channel blocker. The discrepancy may reflect species differences. In their study, however, D600 was added to the EGTA solution for only $5 \mathrm{~min}$, while the muscle was stimulated every $15 \mathrm{~s}$. It seems necessary to confirm that such a short exposure and a low rate of stimulation (cf. LeE and TsIEN, 1983) could build up a sufficient condition for development of the drug action in the frog ventricular muscle.

Ca channel current carried by monovalent cations. In many types of preparations, monovalent cations are capable of carrying currents through the $\mathrm{Ca}$ channel, either at large positive potentials or in the absence of external $\mathrm{Ca}$. The kinetic property of the monovalent cation current has been reported. FuKUSHIMA and Hagrwara (1985) showed that the decay time constant was similar to that of the ordinary Ca current in mouse B lymphocytes. Similar observations have been made in molluscan neurons (KosTYUK and KRISHTAL, 1977) and frog skeletal muscle fiber (Almers and MCCLESKEY, 1984). In cardiac muscle, few studies have been directed to this point (RougIER et al., 1969, see above). Our results show that the current induced by EGTA Tyrode in ventricular cells had a time-dependence different from that of the normal $I_{\mathrm{Ca}}$. This may indicate a specificity of the cardiac $\mathrm{Ca}$ channel. Further studies are necessary to elucidate the nature of the changes in current kinetics, observed in EGTA Tyrode.

The outward current evoked at high voltages in EGTA Tyrode was considered to include a $\mathrm{Ca}$ channel current carried by $\mathrm{K}$ ions. Outward $\mathrm{Ca}$ channel currents, attributed to monovalent cations, have been observed in guinea-pig ventricular cells at large positive potentials in the presence of external Ca (LEE and TsIEN, 1982, 1984). Similar currents were also noted in bovine chromaffin cells (FENWICK et al., 1982), and mouse B lymphocytes (FuKushima and HaGiwara, 1985). On the other hand, MATSuda and Noma (1984) considered the voltagedependent leakage conductance as a cause of the decaying outward current, which was observed at large positive potentials in guinea-pig ventricular cells ex- 
posed to Na-free, K-free, Ca-containing solutions. Their finding was, that this current was not affected by pre-depolarizations. Thus, the nature of the outward current developing at high voltages, in the presence of $\mathrm{Ca}$, appears to be controversial in the case of guinea-pig ventricular cells. In our study, the outward current in question clearly showed a voltage-dependent inactivation (Fig. 4), which is in agreement with the observation of LEE and TsIEN (1982). Although the difference may relate to the experimental conditions, at least in the case of the absence of $\mathrm{Ca}$, the slow channel in guinea-pig ventricular cells seems to allow an outflow of $\mathrm{K}$ ions.

This research was supported by Grants-in-Aid for Scientific Research from the Ministry of Education, Science and Culture of Japan (57480104, MG; 57580034, TE). We thank M. Ohara, Kyushu University, for her critical reading of the manuscript.

\section{REFERENCES}

Almers, W. and McCleskey, E. W. (1984) Non-selective conductance in calcium channels of frog muscle; calcium selectivity in a single-file pore. J. Physiol. (Lond.), 353: 599-608.

Fenwick, E. M., Marty, A., and Neher, E. (1982) Sodium and calcium channels in bovine chromaffin cells. J. Physiol. (Lond.), 331: 599-635.

Fukushima, Y. and Hagiwara, S. (1985) Currents carried by monovalent cations through calcium channels in mouse neoplastic B lymphocytes. J. Physiol. (Lond.), 358: 255-284.

Garnier, D., Rougier, O., GargouïL, Y. M., and Coraboeuf, E. (1969) Analyse électrophysiologique du plateau des réponses myocardiques, mise en evidence d'un courant lent entrant enabsence d'ions bivalents. Pflügers Arch., 313: 321-342.

Goто, M. and AвE, Y. (1964) Effects of 'EDTA' on the membrane potential and tension of ventricular muscle of the rabbit. Jpn. J. Physiol., 14: 135-146.

Goto, M., URATA, M., and Hyodo, T. (1982) Instantaneous and delayed outward currents of the bullfrog atrial muscle in Ca-free or Na-deficient conditions. Jpn. J. Physiol., 32: 573587.

Hamill, O. P., Marty, A., Neher, E., Sakmann, B., and Sigworth, F. J. (1981) Improved patch-clamp techniques for high-resolution current recording from cells and cell-free membrane patches. Pflügers Arch., 391: 85-100.

HaRafuit, H. and Ogawa, Y. (1980) Re-examination of the apparent binding constant of ethylene glycol bis ( $\beta$-aminoethyl ether)- $N, N, N^{\prime}, N^{\prime}$-tetraacetic acid with calcium around neutral pH. J. Biochem., 87: 1305-1312.

Hoffman, B. F. and SucKLING, E. E. (1956) Effect of several cations on transmembrane potentials of cardiac muscles. Am. J. Physiol., 186: 317-324.

IRISAWA, H. and KoKUBUN, S. (1983) Modulation by intracellular ATP and cyclic AMP of the slow inward current in isolated single ventricular cells of the guinea-pig. J. Physiol. (Lond.), 338: 321-337.

IsENBERG, G. and KLöCKNER, U. (1982a) Calcium tolerant ventricular myocytes prepared by preincubation in a "KB Medium." Pflügers Arch., 395: 6-18.

ISENBERG, G. and KLÖCKNER, U. (1982b) Calcium currents of isolated bovine ventricular myocytes are fast and of large amplitude. Pfügers Arch., 395: 30-41.

Josephson, I. R., SANChez-Chapula, J., and Brown, A. M. (1984) A comparison of calcium currents in rat and guinea-pig single ventricular cells. Circ. Res., 54: 144-156.

KenYon, J. L. and Gibbons, W. R. (1979) 4-Aminopyridine and the early outward current of

Vol. 35 , No. 6,1985 
sheep cardiac Purkinje fibers. J. Gen. Physiol., 73: 139-157.

KostyUK, P. G. and KRISHTAL, O. A. (1977) Effects of calcium and calcium-chelating agents on the inward and outward current in the membrane of mollusc neurones. J. Physiol. (Lond.), 270: $569-580$.

LeE, K. S. and TsIEN, R. W. (1982) Reversal of current through calcium channels in dialysed single heart cells. Nature, 297: 498-501.

LEE, K.S. and TsIEN, R. W. (1983) Mechanism of calcium channel blockade by verapamil, D600, diltiazem and nitrendipine in signle dialysed heart cells. Nature, 302: 790-794.

LEE, K. S. and Tsien, R. W. (1984) High selectivity of calcium channels in single dialysed heart cells of the guinea-pig. J. Physiol. (Lond.), 354: 253-272.

Matsuda, H. and Noma, A. (1984) Isolation of calcium current and its sensitivity to monovalent cations in dialysed ventricular cells of guinea-pig. J. Physiol. (Lond.), 357: 553-573.

Miller, D. J. and Moisescu, D. G. (1976) The effects of very low external calcium and sodium concentrations on cardiac contractile strength and calcium-sodium antagonism. J. Physiol. (Lond.), 259: 283-308.

Miller, D. J. and MörChen, A. (1978) On the effects of divalent cations and ethylene glycolbis-( $\beta$-aminoethyl ether)- $N, N, N^{\prime}, N^{\prime}$-tetraacetate on action potential duration in frog heart. J. Gen. Physiol., 71: 47-67.

Rougier, O., Vassort. G., Garnier, D., Gargouil, Y. M., and Coraboeuf, E. (1969) Existence and role of a slow inward current during the frog atrial action potential. Pfügers Arch., 308: 91-110.

Tritthart, H., Macleod, D. P., Stierle, H. E., and Krause, H. (1973) Effects of Ca-free and EDTA-containing Tyrode solution on transmembrane electrical activity and contraction in guinea-pig papillary muscle. Pflügers Arch., 338: 361-376.

Urata, M. and Goto, M. (1982) Membrane currents related to configuration changes in the action potential of frog atrial muscle in $\mathrm{Na}$ - and $\mathrm{Ca}$-free conditions. J. Mol. Cell. Cardiol., 14: 371-379.

YATANI, A., Iмото, Y., and Goto, M. (1984) The effects of caffeine on the electrical properties of isolated, single rat ventricular cells. Jpn. J. Physiol., 34: 337-349. 